\title{
Toward a New Design Philosophy of HCI: Knowledge of Collaborative Action of "We" Human-and-Technology
}

\author{
HyunKyoung Cho ${ }^{1}$ and Joonsung Yoon ${ }^{2}$ \\ ${ }^{1}$ GIST, Cultural Technology Institute, Korea \\ hkcho@gist.ac.kr \\ ${ }^{2}$ Global School of Media, Soongsil University, Korea \\ dryoon@maat.kr
}

\begin{abstract}
This research examines a new design philosophy of HCI in the collaborative action-based context interdependent perspective. To frame a new perspective of design philosophy of interactive technologies, the study proposes "We" human-and-technology as a response for alternative perspectives of reference in inter-active systems design and alternative ways of understanding the relationships and collaborative actions between humans and new digital technologies. It argues the problem of knowledge provoked by the collaborative action of "We" human-and-technology, through three keys: reflecting, performing, and invaginating. Its aim is to reveal that $\mathrm{HCI}$ design practices establish a new knowledge beyond the logic of opposition reinforcing the mutual degradation between technology and human, thought and action, subject and object.
\end{abstract}

Keywords: "We" human-and-technology, collaborative action, knowledge, reflecting, performing, invaginating, HCI design.

\section{Introduction}

The only action corresponds to the human condition; the human existence and its condition. The way in which we humans produce our means of life articulates itself in the mode of performing our life beyond the material and physical one. The human condition is a whole from the perspective of the idea of social relations embodied in the real movement of life. It designates the knowledge as the intertwinement of reason and experience in the actual life-process.

Max Horkheimer and Theodor W. Adorno define the human condition as a paradox of knowledge embracing both enlightenment and myth. It has the twofold character of enlightenment traversing the universal movement of mind and a nihilistic, life-denying power [1]. ${ }^{1}$ On the one hand, we humans create our own condition, and on the other, everything we create turns immediately into a condition. This implies that the human existence and its condition supplement each other, so long as the supplementation assumes that the human condition can be transformed by the performing of action. Here the problematic is that like human-human communication,

\footnotetext{
${ }^{1}$ Max Horkheimer and Theodor W. Adorno, Dialectic of Enlightenment (California, Standford: Standford University Press, 2002), p. 36.
} 
technology and humans act and react. In particular, computational technology is endowed with highly intelligent and perceptive qualities; has its own laws; and the system itself evolves. With the ability of autonomy and emergence, technology performs the autonomous and emergent action beyond human control. It becomes 'a performer (a collaborator)' collaborating with humans [2]. ${ }^{2}$

Technology as performer (collaborator) transforms the human condition. The transformation, the expanded human condition by the collaborative action of we humans and technology can be called as "We" human-and-technology. The word of "We" human-and-technology indicates that identity of we humans is organized by collaborative actions between we humans and technology in HCI design. "We" human-andtechnology is a response to the need for alternative frames of reference in inter-active systems design and alternative ways of understanding the relationships and collaborative actions between humans and new digital technologies. It is to point to a growing interest in the design philosophy of interactive technologies.
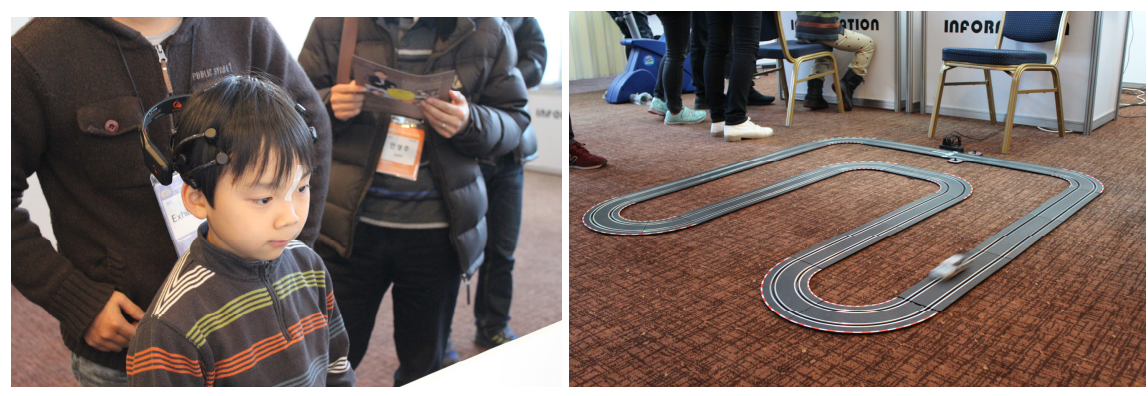

Fig. 1. HCI Design with BCI, Brain-Computer Collaborative Action: Racing Car Game designed by Bio-Computing Laboratory at GIST, Korea. EPOC and Carrera Slot Car. ${ }^{3}$

HCI design techniques evolve beyond conscious or direct inputs. Especially, HCI design with Brain-Computer Interface (BCI) shows that the collaborative action of "We" human-and-technology involves both conscious and non-conscious inputs. It expands the collaborative action into a kind of biofeedback. It suggests the brainsignal processing as a new way for collaborative action of "We" human-andtechnology.

For example, Racing Car Game (Fig.1) as an ongoing research-led practice about the design of HCI with BCI is constituted by the concentration between human and computer as collaborators. The brain-computer collaborative action changes the car's velocity; it can improve the attention state; when the collaboration between human and computer gets stronger, the concentration level goes higher. In Racing Car Game, brainwave is the key measure. It represents the concentration as the degree of

\footnotetext{
${ }^{2}$ The concept of collaborative action was first presented in HyunKyoung Cho and Joonsung Yoon, "Performative Art: The Politics of Doubleness," Leonardo, 42:3 (New York: The MIT Press, 2009), pp. 282-283.

${ }^{3}$ EPOC is as a 14-channel wireless EEG system developed by Emotiv Systems.
} 
collaborative action of "We" human-and-technology. Car's velocity shows the concentration level using electroencephalography (EEG). Racing Car Game's system is implemented under BCI2000 platform (general purpose software in BCI research). Graphical software visualizes concentration index, and hardware module controls the velocity of a racing car.

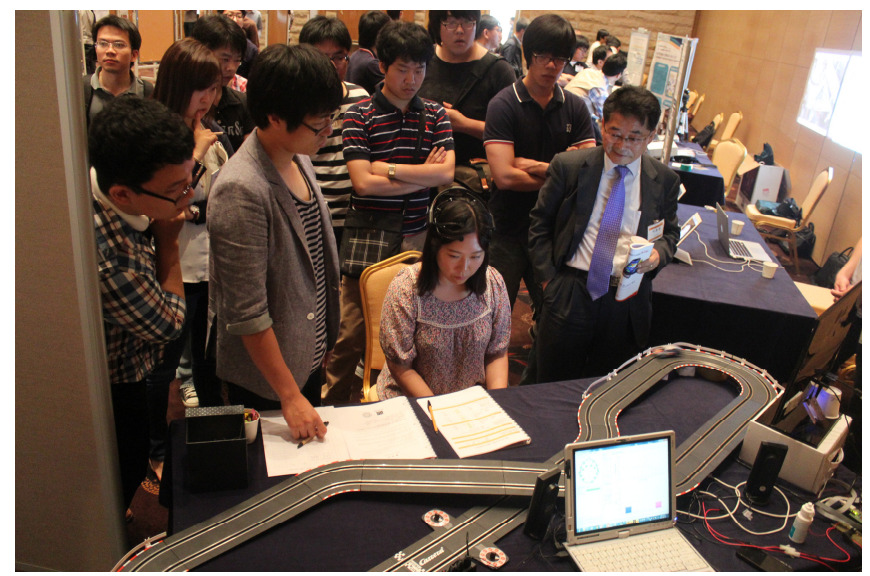

Fig. 2. Brain Game of "We" human-and-technology: Communication without physical and visible movement ${ }^{4}$

As a new way of HCI design for "We" human-and-technology, the collaborative action through brain activities allows us a communication without physical and visible movement between human and computer (Fig.2). Brain signals create a new philosophical and aesthetic dimension of HCI design constituted by the collaborative action of "We" human-and-technology. In HCI design practices, the collaborative action of "We" human-and-technology becomes an imagination itself; in terms of communications without physical and visible movement and interface. BrainComputer Interactive design considers the collaborative action of "We" human-andtechnology as both knowledge of practical arts and practical arts themselves. It presents that HCI design constituted by collaborative action of "We" human-andtechnology stimulates a network of conceptual relations rather than merely perceptions of the visible aspects of singles works.

\section{Reflecting}

The collaborative action of "We" human-and-technology reflects the knowledge concealing the live relations between technology and human. The human subject-centered

\footnotetext{
${ }^{4}$ Racing Car Game Exhibition. The design of HCI with BCI is a part of my ongoing research project, "Arts in Laboratory: the aesthetic reconstruction of technological experiments."
} 
dichotomy assumes that human controls actions at his own will, while technology is a simple technological tool. It fosters the instrumental understanding on the relationship of technology and human. It defines the collaboration of technology and human as the represented relation that expresses the subjective experience through the representation of object. In the knowledge excluding technology as an equal partner, both the technology and humans are subordinated into the instrumental, and the interaction between them remains an impure one, a means to represent the knowledge itself (the knowledge system).

As a new philosophy of HCI design, knowledge of collaborative action of "We" human-and-technology rejects the instrumental rationality, the idea that underlines the collaborative action of "We" human-and-technology as a tool to express the represented knowledge. It might be a solution to overcoming human-subject centered instrumental knowledge. HCI design of "We" human-and-technology proposes a collaborative perspective; 'the collaborative being-with-the technology in the world' [3]. It restores the significance of action as what happens in the realm of the performing, and saves the real, lived, and free relation between technology and humans. It ultimately cultivates 'the spirit of humanity' that allows us to be critical, the examined and liberal life from the bondage of habit and custom [4]. ${ }^{6}$

In HCI design practices, the collaborative action of "We" human-and-technology reflects the history of action that has been degraded into the instrument to represent thinking. It embraces both the history of ideas (the analysis of systems of representations) and the history of mentalities (the analysis of attitudes and type of action). The reflecting knowledge of HCI design of "We" human-and-technology presents that action is an apex of human activities, insofar as it testifies the multiplicity as the essence of life. In digital environments, the newness is that technology plays a role as a performer (a collaborator) like a human, and the process of technology-human interaction follows the logic of human communication; technology and humans directly acts and reacts as a human-human communication. This reflection of HCI design constituted by the collaborative action of "We" human-and-technology changes what the human is doing; how humans act. It insists that the definition of human action should be reconsidered in the collaborative relationship with technology.

A new philosophy of HCI design stresses that technology and humans reciprocally share the action's process and its result. This sharing weaves a hybrid network constituted by performers (collaborators) in an equitable manner. Thus HCI design performed by collaborative action of "We" human-and-technology leads us to a radical shift of knowledge/power on two points: from the human subject-centered dichotomy to the inter-subjective networking, from knowledge qua thinking to that qua acting. The shifts retain the knowledge, its great intelligence, which does reflect the new human identity constituted by the collaborative action of "We" human-andtechnology.

\footnotetext{
${ }^{5}$ Martin Heidegger, Being and Time (London: Blackwell Publishing, 1962).

${ }^{6}$ Martha C. Nussbaum, Cultivating Humanity: A Classical Defense of Reform in Liberal Education (Cambridge: Harvard University Press, 2003).
} 


\section{$3 \quad$ Performing}

The collaborative action of "We" human-and-technology is amplified by design practices of HCI. One of significance quietness of HCI design is that the collaborative action of "We" human-and-technology becomes work itself. As equal collaborators, human and technology communicate using actions, and there is nothing without theirs equal collaboration. The collaborative action of "We" human-and-technology has a structure of reciprocal conversation. In HCI design practices, the process of when the collaborative action of "We" human-and-technology is performed involves with the performative [5]. ${ }^{7}$

In this linguistic concept, HCI design of "We" human- and-technology can be considered as a kind of utterance, and the performative action is characterized by the fact that the performativity articulates what happens, embracing action itself as well as consequences and effects of action beyond the propositional content. At this point, HCI design performed by the collaborative action of "We" human-and-technology becomes actually an open work against the fixed meaning and authority.

Within the performing knowledge of HCI design, actions cause epistemological troubles. As a point where we humans meet technology, the performative of HCI design of "We" human-and-technology critiques essentially a fundamental failure of instrumental knowledge based on the logic of opposition. It reveals that the binary frame hides itself from the ways that instrumental knowledge necessarily depends on and requires exclusion. The binary frame is based on homonymous heteronomy. The problem is that the instrumental produces an empty equality because it identifies parts as the part which is separated from the sum of the parts. Although parts identify as a whole, as an entity of equal parts, they are not a whole of equals inasmuch as the instrumental distinguishes between ruler and ruled, inferior and superiors. Instead of an empty idea, HCI design performed by the collaborative action of human and technology notes the network of equals. It means that as a new way introduced by technology, a new notion of the relation of we humans and technology is a network constituted by equality of parts that have no part. It justifies that there is a contesting collaboration between equal parts.

When HCI design is performed by "We" human-and-technology, the relation of we humans and technology is in the 'doing.' The 'doing' related to the placing of 'does' is a curious act especially in a context that would avoid the representational

\footnotetext{
${ }^{7}$ As J.L Austin's linguistic observations of speech act, performativity is defined as "to say something is to do something." It indicates that the issuing of an utterance is performing not description or representation of actions, but actions. It is identified with the illocutionary and perlocutionary act depending on the extent of consequences and effects arising from the speech act: according to speech act theory, illocutionary acts have certain consequences beyond the propositional content, and perlocutionary acts are utterances that generate a chain of effects. J. L. Austin, How to Do Things with Words (Cambridge, MA: Harvard University Press, 1975).
} 
knowledge in which we humans and technology are tied to the instrumental rationality. The regime of representation assumes that 'to do' is to represent. However, knowledge of HCI design performed by collaborative action of "We" human-andtechnology insist that 'to do' is to present: 'to do' is what happens in the regime of presentation. 'To do' denies that one of them, humans or technology, determines what is significant and what is not. 'To do' asks questions why must the relation of "We" human-and-technology be placed within one of them?

As the doing of a network of equal parts, HCI design of "We" human-andtechnology presents a new definition of the relation of we humans and technology as a way that we perform. We have to perform to know who we are (the characteristics of "We" human-and-technology). The relation between we humans and technology is a mobilization, and thus it misses its own movement. Although "We" human-andtechnology is a relation as such, it is not there because it is in the process of happening: it can be addressed as an utterance: a system beyond two systems of thought and action. The visibility of relation that is not there is embodied as a performative way of linking meaning and action, of framing the relation between the sayable and the visible.

In other words, HCI design of "We" human-and-technology happens as 'to do' as it makes visible the system of meaning in real time. It is not a question of meaning being represented by an action. Instead, meaning is understood as action, something that does. And, in that process of 'to do', it attains the performative as the visible. With this performing knowledge of HCI design, the relation of we humans and technology occurs. This occurrence critiques the instrumentalization of technology: the historical and critical ease with which technology is confined to the instrumental. On the other hand, it challenges the idealization of action: an account of action as a form of representation.

As a result, HCI design performed by collaborative action of "We" human-andtechnology becomes the non-representational link between two systems of meaning and action. It attains the position of a collaborative relation without characterizing it in either positive or negative terms. It pushes the realm of representational politics to a negative extreme. At the same time, it embraces the significance of its desired social critique and the politics that such a desire assumes. The relation of we humans and technology therefore is in the double determination of commonality and exclusivity. It establishes at one and the same time something common that is both shared and exclusive parts. This double determination structures a network so that everything possessing visibility is assigned a part. The network recalls the "actant-network" in Bruno Latour's insight to embrace both "actors" (who act) and "systems" (which behave) [6]. ${ }^{8}$ In the performing of HCI design, the relation of we humans and technology is a contested collaboration between actants (equal parts). Here, to become visible is that the relation takes place in equality: in order for mobilization to become visible, the relation must take place in equality. In other words, the equality between actants in network marks a collaboration that arises as soon as actants contest their invisibility

\footnotetext{
${ }^{8}$ Bruno Latour, We Have Never Been Modern (Cambridge: Harvard University Press, 1993).
} 
by the performative. This contesting collaboration is the rational occasion of "We" human-and-technology. As a result, equality cannot be recognized as the object or issue of relation between we humans and technology.

The performativity of contesting collaboration between actants in network is a source for HCI design practices. Through the performing of knowledge, HCI design of "We" human-and-technology enable us to examine further and better identify the notion of individual and social freedom. It provides the key for self-criticism (selfawareness) to decipher our reality. It recalls that "Man's condition, his protects and collaboration with others on tasks that strengthen man's totality, are new issues which require genuine inspiration [7]."

\section{$4 \quad$ Invaginating}

Knowledge of HCI design constituted by collaborative action of "We" human-andtechnology is invaginatory [8][9]. ${ }^{10}$ It works in the terrain of the confrontation between the question and its answer. Instead of drawing a line of demarcation between question and answer, it invaginates the two into a solution. Here the invaginating is a 'seeking' to necessity of asking of an answering in a questioning (inquiry). It is an active 'investigating' for an entity both with regard to the fact that the problem of collaborative action is, and with regard to its reading as it is. It is guided beforehand by what is sought. Insofar as seeking something incorporates that which is asked about, knowledge is somehow an investigative questioning of something. In addition to what is asked about, there is a seeking of that which is interrogated.

In this case, HCI design of "We" human-and-technology is a seeking questioning of a movement of critical analysis in which one tries to read how the different questions and answers to the problem have been constructed; but also how theses different questions and answers result from its problem. It appears that any new solutions that might be added to the others would arise from the current problem of knowledge. At this point, we could say that knowledge of HCI design performed by of collaborative action of "We" human-and-technology repeats one another. The essential point is that it is not a mere folding but an immanent and synthetic repetition. It produces the reiterating differences of self-reference in the self-reflexivity.

Especially, HCI design intervenes in power and knowledge relations. It questions the problem of knowledge itself, and poses its answer within its problem. The

\footnotetext{
${ }^{9}$ Frantz Fanon, The Wretched of The Earth (New York: Grove Press, 2004), p. 236.

${ }^{10}$ In this study, the concept of invagination refers to Jacques Derrida and Rosaline Krauss's notion. In the discourse of the narrative, Derrida describes it as "the folding of one story within another through the invention of a character who exactly repeats the opening of the first story, thereby setting it off on its narrative course once more." Krauss applies Derrida's notion into the modernist reflexivity of post-medium supported by technology. Derrida, "The Law of Genre," Glyph 7 (Baltimore: Johns Hopkins University Press, 1980), pp.202-232. Rosaline Krauss, "Two Moments from the Post-Medium Condition," OCTOBER, Vol.116, No.1, Spring (New York: The MIT Press, 2006), pp.55-62.
} 
re-conception of knowledge within knowledge reveals an essential lack of the knowledge based on the dichotomy, the binary frame. This lack can be explained with the understanding of supplementation. Philosophy as a knowledge defines the word 'supplement' as something that completes or makes an addition to complete. It means that the supplement supports both completeness and un-completeness, and thus its understanding can be invested in the indeterminacy. However, the supplementary structure has been considered in one perspective that defines the supplement as 'an inessential extra, added to something complete it in itself' [10][11]. ${ }^{11}$

The supplement serves to enhance the presence of something that is already complete and self-sufficient. This idea reinforces the dichotomy based on the logic of opposition; this perspective presupposes that the action is a supplement of thought; the object is a supplement of subject; technology is a supplement of humans. When knowledge is rooted from the supplementary structure supporting the logic of opposition, the so-called desire for the neutral such as performed knowledge is degraded as the immoral, ugly, and even dangerous. For example, in a dichotomy, the idea of a university is an attitude (experience) of human subject that represents knowledge of the object for the thinking practice. Judgment depends on the laws of morality and reason based on the logic of opposition of moral and immoral, good and evil; wherein what is universal is parallel to what is moral and good.

As an intervention on the knowledge/power system based on the logic of opposition, HCI design of "We" human-and-technology admits the supplementary structure's incompleteness as the surplus derived from its essential lack [12]. ${ }^{12}$ Insofar as the supplement is defined as an unessential extra addition to completeness itself, it is exactly what was supposed to be complete in itself. It grants that there is a hole originated from the incompleteness of the supplementary structure itself.

The invaginating knowledge of HCI design explains that the supplement does not enhance the completeness's presence, but rather underscores its absence. When the absence, the hole should be filled by something, it is an essential lack. The lack evolves with a desire organized in the relation to action to object. The failure of action

${ }^{11}$ The logic of supplement was taken from Jean Jacques Rousseau. He used the term in order to explain the relationship between speech and writing. Derrida revisited Rousseau's logic of speech supplement. Rousseau notes that writing may become a 'dangerous supplement,' if it is used as a substitute for speech. Whereas, Derrida states that writing can be the supplement of speech. Even if writing is viewed as a supplement to speech, writing may still add meaning to speech, and it may still provide a kind of presence. Here, Derrida's emphasis is that there is an original lack of the supplementary structure rooted in Western thinking. In order to avoid the supplement between writing and speech, Derrida invokes the term invagination. Derrida, Of Grammatology (Baltimore: Johns Hopkins University Press, 1998), and "Signature Event Context," Limited Inc (Evanston, IL: Northwestern University Press, 1988) pp.1-24.

12 The word 'lack' was used in Jacque Lacan's view. See, Lacan's "On Freud's “Trieb” and the Psychoanalysis's Desire,” Ecrits (New York: W.W. Norton \& Company, 2005),pp.721-725. Derrida also used the term 'lack' in the discussion of structure. He insists that the supplement is to fill the original lack of Western thinking. 
towards the impossible and untouchable object is what we call knowledge as reality constituted by the Real [13]. ${ }^{13}$

Acknowledgments. This research is supported by Ministry of Culture, Sports and Tourism (MCST) and Korea Creative Content Agency (KOCCA) in the Culture Technology (CT) Research \& Development Program 2012.

\section{References}

1. Horkheimer, M., Adorno, T.W.: Dialectic of Enlightenment. Stanford University Press, California (2002)

2. Cho, H.K., Yoon, J.S.: Performative Art: The Politics of Doubleness. Leonardo 42(3), 282-283 (2009)

3. Heidegger, M.: Being and Time. Blackwell Publishing, London (1962)

4. Nussbaum, M.C.: Cultivating Humanity: A Classical Defense of Reform in Liberal Education. Harvard University Press, Cambridge (2003)

5. Austin, J.L.: How to Do Things with Words. Harvard University Press, Cambridge (1975)

6. Latour, B.: We Have Never Been Modern. Harvard University Press, Cambridge (1993)

7. Fanon, F.: The Wretched of the Earth. Grove Press, New York (2004)

8. Derrida, J.: The Law of Genre. In: Glyph 7. Johns Hopkins University Press, Baltimore (1980)

9. Krauss, R.: Two Moments from the Post-Medium Condition. October 116(1) (Spring 2006)

10. Derrida, J.: Of Grammatology. Johns Hopkins University Press, Baltimore (1998)

11. Derrida, J.: Signature Event Context. In: Limited Inc. Northwestern University Press, Evanston (1988)

12. Lacan, J.: Ecrits. W.W. Norton \&Company, New York (2005)

13. Marx, K., Engles, F.: The German Ideology. International Publishers Co., New York (1970)

${ }^{13}$ Lacanian notion of reality and the Real cannot be explained in the ideology that emphasizes the completeness of the supplementary structure. Lacan defines the reality as an image projected by the Real. This means that the reality is constitutive of the Real. Here, it should be mentioned that the relationship of reality and the Real does not to the completeness as the One, insofar as the reality is constituted by the Real. In the case, the Real is no less than the impossible, uncomplete. At this point, there is a parallel between Lacan and Marx's insight. Marx emphasizes that the real and lived relation (the human condition) is constituted by the actual life-process, not the consciousness. When Marx denies the reality constituted by its consciousness, Marx's 'the actual life-process' corresponds to Lacan's the Real. What both Marx and Lacan want to read is ultimately the problem of knowledge that reinforces the completeness what is supposed to be complete in itself. For the further study of Marx's insight, see Karl Marx and Friedrich Engles, The German Ideology (New York: International Publishers Co., 1970). 